\title{
Resisting Gendered Smoking Pressures: Critical Consciousness as a Correlate of Women's Smoking Status
}

\author{
Alyssa N. Zucker, ${ }^{1,5}$ Abigail J. Stewart, ${ }^{2}$ Cynthia S. Pomerleau, ${ }^{3}$ \\ and Carol J. Boyd ${ }^{4}$
}

Gender is one of the social structures, along with social class and ethnicity, that shapes women's smoking behaviors. We examined how different responses to gender pressures (internalization and resistance) relate to smoking. We analyzed data from a national random digit dial survey of 945 women and found that never smokers scored high on resistance to gender pressure (indicated by high scores on feminist consciousness) and on education and Body Mass Index; current smokers had the reverse pattern. Ex-smokers scored high on one measure of resistance (advertising skepticism) and on two measures of internalization (embodied femininity and weight concern); they were also likely to have high household income and to be European American. Results are discussed in terms of their implications for smoking cessation programs and antismoking campaigns.

KEY WORDS: cigarette smoking; feminist consciousness; advertising skepticism.

The American public has known since 1964 that smoking is a health risk behavior (Centers for Disease Control and Prevention [CDC], 2004a). Tobacco use remains the leading preventable cause of morbidity and mortality in the United States, and it results in more than $\$ 75$ billion in direct costs annually (CDC, 2004b). Yet despite the known risks of cigarette smoking, approximately 4,000 people under the age of 18 try their first cigarette each day, and roughly $22.5 \%$ of the population $(20 \%$ of women

\footnotetext{
${ }^{1}$ Department of Psychology, and Program in Women's Studies, George Washington University.

${ }^{2}$ Department of Psychology, Program in Women's Studies, and Institute for Research on Women and Gender, University of Michigan, Ann Arbor, Michigan.

${ }^{3}$ Nicotine Research Laboratory, Department of Psychiatry, and Substance Abuse Research Center, University of Michigan.

${ }^{4}$ School of Nursing and Substance Abuse Research Center, University of Michigan.

${ }^{5}$ To whom correspondence should be addressed at Program in Women's Studies, George Washington University, 837 22nd St. NW, Washington, District of Columbia 20052; e-mail: azucker@ gwu.edu.
}

and $25.2 \%$ of men) were current smokers as of 2002 (CDC, 2004c). Clearly there is a paradox here: why would people continue to engage in a behavior that will contribute to the deterioration of their quality of life and possibly their early demise? Part of the answer lies in the fact that nicotine is an addictive drug, but social structural factors, such as gender, ethnicity, and social class, also contribute through their influence on both the stressors and resources in individuals' lives. In this study we examined two of these social structures (ethnicity and social class) in terms that are standard, but are not capable of offering insight into the psychology of smoking behavior. We did this knowing that these factors are important correlates of smoking behavior (and therefore must be included), but our focus is on understanding some of the reasons that a third structuregender-is also an important correlate of smoking behavior. We examined the potential role of genderrelated pressures for thinness in fostering, and of individual critical consciousness in constraining, smoking behavior among women. 


\section{Social Structure and Smoking}

Social values and beliefs regarding gender provide a social structure that shapes smoking behavior (Graham, 1992; Jacobson, 1982; MacDonald \& Wright, 2002; Pfau, Nelson, \& Moster, 1996). American girls and women are subject to pressures to attain an unrealistically thin body (e.g., Heinberg \& Thompson, 1995), and, as a result, many women internalize extreme beauty standards (Bordo, 1993; Chernin, 1981; Wolf, 1991) and are discontented with their bodies (Cash \& Henry, 1995; Field et al., 1999; Rodin, Silberstein, \& Striegel-Moore, 1984). Because cigarette smoking is widely associated with weight loss or maintenance, some women are vulnerable to using smoking as a weight control mechanism (Gerend, Boyle, Peterson, \& Hatsukami, 1998; Klesges \& Klesges, 1988; Pomerleau, Berman, Gritz, Marks, \& Goeters, 1994; Zucker et al., 2001). The cigarette industry takes advantage of this vulnerability and differentially targets the values held by women and men (Boyd, 1996-1997; Boyd, Boyd, \& Cash, 1999-2000; Boyd, Boyd \& Greelee, 2003; Cortese, 1999; Ernster, 1985; Kellner, 1988). For instance, cigarette advertisements aimed at women have used images of weight control since early in the twentieth century, whereas advertising aimed at men has emphasized images of independence, activity, and the outdoors (Boyd et al., 1999-2000; Kellner, 1988). Thus, when women internalize gender messages about the value of thinness, they may be at particular risk for engaging in smoking.

Several studies have shown that, in addition to smoking for weight control, women may smoke for reasons that are related to their lower social status, or because they feel trapped in the roles of wife and mother (Bancroft, Wiltshire, Parry, \& Amos, 2003; Graham, 1992; Jacobson, 1982; MacDonald \& Wright, 2002; Pohl \& Caplan, 1998). For instance, Jacobson quoted one woman who said "I think I smoke from boredom and despair, there being no foreseeable end to my marriage predicament" (p. 42).

Women's smoking behaviors are further complicated by their membership in other demographic groups, on the basis of ethnicity, age, and socioeconomic status. Smoking rates differ among women of different ethnic groups (e.g., Smith \& Fiore, 1999); Native American women smoke at highest rates (40.9\%), followed by European Americans (21.8\%), African Americans (18.7\%), Latinas (10.8\%), and Asian American women (6.5\%; CDC, 2004c). These differences in smoking prevalence may be a function of cultural beliefs and norms, or of an interaction of ethnicity with poverty. Although all women are susceptible to thin beauty ideals, and thus may smoke for weight control, some evidence suggests that European American women may be particularly vulnerable (Fallon, 1990; Harris, 1994). Women also differ in their smoking rates across the lifespan. Smoking prevalence is highest for women aged 1824 years $(24.6 \%)$ and then decreases with age: age 25-44 (22.8\%), age 45-64 (21.1\%), age 65 and older (8.6\%; CDC 2004b). Pregnancy and parenthood often serve as motivations for quitting during young adulthood (e.g., Condit, 1996).

Socioeconomic status, most often assessed by the proxy variables of education and income, is a powerful structural correlate of smoking initiation, persistence, and cessation (e.g., Gilman, Abrams, \& Buka, 2003; Harrell, Bangdiwala, Deng, Webb, \& Bradley, 1998; Manfredi, Lacey, Warnecke, \& Petraitis, 1998; Stronks, van de Mheen, Looman, \& Mackenbach, 1997). Smith and Fiore (1999) argued that "among sociodemographic predictors of differences in rates of current smoking, educational attainment has replaced sex as the most predictive characteristic" (p. 439). A wide variety of studies, from a number of countries, find a steep SES gradient in smoking behavior; people from more privileged backgrounds are less likely to initiate smoking, start smoking later if they do smoke, and are more likely to quit smoking (Bancroft et al., 2003; Graham, 1992; Graham \& Der, 1999; Harrell et al., 1998; Jarvis, 1997; Pohl \& Caplan, 1998; Smith \& Fiore, 1999; Stronks et al., 1997).

SES is an indicator of the material conditions of one's life, such as household income and access to high quality health care. Moreover, material conditions include exposure to environmental stressors that may lead to the use of smoking as a coping resource (Stronks et al., 1997). SES may also be an indicator of shared cultural beliefs that shape health practices. One study found that people from low and high SES backgrounds differed in terms of how they defined health, the level of personal control they felt over their health, and their perceived susceptibility to smoking-related illnesses (Chamberlain \& O'Neill, 1998). An external locus of control (associated with low SES) may be related to the belief that quitting smoking now will not lead to improved health in the future, or that regardless of one's smoking behavior, one's health outcomes are likely to be poor because of adverse living conditions. These structurally 
based beliefs are strongly related to smoking status (Chamberlain \& O'Neill, 1998; Stronks et al., 1997). We expected, then, that ethnicity, age, education, and income would be key variables to include in any analysis of women's smoking behavior.

\section{Understanding the Role of Gender}

As argued above, women are subject to particular social pressures to have extremely thin bodies, and advertising reinforces cigarettes as one method of weight control. Thus we expected that women who internalize certain "feminine" standards of body shape and appearance (i.e., those who score high on a measure of "embodied femininity"; Bay-Cheng, Zucker, Stewart, \& Pomerleau, 2002) and who are explicitly weight concerned, will be at greater risk for smoking, regardless of whether they are actually overweight.

If internalization of thin body ideals and weight concern represent yielding to gendered norms that in turn relate to smoking, what might constitute resistance? Dedobbeleer, Beland, Contandriopoulos, and Adrian (2004) argued that researchers should employ more individual difference variables to account for gendered smoking behavior. We suggest that two types of critical consciousness are important cultural tools for women in this domain. Both advertising skepticism and feminist consciousness may help women to resist enticing cigarette advertisements by offering them tools for deconstructing the messages presented to them. These are described in detail below.

Western culture is permeated with media images. Data from both the United States and the United Kingdom (Elkind, 1985) show that movies and advertisements have succeeded in shaping women's perceptions of female smokers; they are seen as elegant, glamorous, sexy, and sophisticated. Kellner (1988) analyzed Marlboro and Virginia Slims cigarette advertisements, and argued that these images influence how individuals acquire their identities. He suggested that Marlboros represent masculinity and natural vigor, and Virginia Slims represent modernity, thinness, and women's empowerment. Advertising is, then, an informal "pedagogy which teaches individuals what they need and what they should desire, think, and do to be happy, successful, and genuinely American" (p. 36). Kellner argued that "enabling individuals to gain critical literacy in regard to advertising. . . provides emancipa- tory competencies which enable individuals to resist manipulation by consumer capitalism" (p. 43). According to this reasoning, advertising skepticism is a stance that can counter the effects of advertising, and thus it is the focus of such programs as MediaSharp, a CDC-sponsored media literacy education program aimed at middle and high school aged youth (CDC, 2004d). In one study, Pohl and Caplan (1998) used a feminist, participatory empowerment intervention model to treat low-income women smokers. They were able to raise participants' consciousness about the ways cigarette marketers target women, and they argued that empowerment through knowledge and efficacy can affect quitting. We expected that individuals who are skeptical of advertising would possess a cultural tool that could help them to resist cigarette advertisements and, therefore, smoking.

As Pohl and Caplan's study shows, feminist consciousness can lead to an analysis of the genderlinked pressure to smoke. However, this analysis may or may not focus particularly on advertising pressures. Instead, feminist consciousness may much more diffusely sensitize women to the presence of gendered social norms and pressures that disadvantage women (Crawford \& Unger, 2004). In this study we relied on Gurin and her colleagues' (Gurin, Miller, \& Gurin, 1980; Gurin \& Townsend, 1986) conception of a cognitive awareness that is at the core of feminist consciousness; they conceptualized feminist consciousness as leading women to recognize their group membership, to feel close to other women, to be conscious of power inequities related to gender, and to attribute these inequities to systematic rather than individual causes.

Some have argued, contrary to the logic we have just outlined, that feminism can be implicated in promoting women's smoking behavior (Elkind, 1985; Pampel, 2003). For instance, Rausch, Hopp, and White (1987) suggested that feminism led to the changing roles of women in the 1970s, which in turn made smoking a more acceptable "feminine" behavior. Certainly the early Virginia Slims advertising campaign and tagline "You've come a long way, baby" capitalized on the changes wrought by the women's movement and equated smoking with emancipation (Boyd et al., 2003; Britton, 1998; Kellner, 1988). Outside the United States, in the 1990s, a brand called "Ms." was targeted to emancipated women in India, and two women's brands were released in China (Kaufman \& Nichter, 2001, as cited in Morrow, Ngoc, Hoang, \& Trinh, 2002). 
Jacobson (1982), however, argued against the idea that feminism promotes smoking and cited data to show that women who were nonsmokers were just as likely as women who smoked to identify with the women's movement. Another study presented conflicting evidence to suggest that feminism was associated with smoking in the early twentieth century, but no longer is (Waldron, 1991). To assess these competing hypotheses, we decided not only to examine whether feminist consciousness is related to smoking status, but also (among smokers and ex-smokers) whether it correlates with endorsing "independence" and "liberation" as reasons for smoking initiation.

Feminism is, in part, a powerful explanatory framework that emphasizes critical analysis skills (Peet \& Reed, 1999; Zucker et al., 2001). Feminists, therefore, are well-positioned to recognize the ways in which the mainstream media in general, and cigarette advertisements in particular, objectify women's bodies, and feminists frequently critique these institutions and their harmful effects (e.g., Kilbourne, 1994). Holding feminist beliefs may serve as a protective factor against smoking by allowing women to deconstruct the cigarette advertisements that display unrealistically thin models and use a variety of techniques to raise women's anxiety about their body image and self worth (Boyd et al., 1999-2000). Previously we found smokers' feminist consciousness was a significant negative correlate of smoking for weight control (Zucker et al., 2001). In this study we expected current smokers to have lower levels of feminist consciousness than ex- and never smokers.

\section{Predicting Smoking Status}

In any prediction of smoking status, it is important to include the demographic variables (e.g., SES, ethnicity, age) that serve as proxies for material conditions that relate to smoking behavior. In addition to those, we expected to see a particular pattern of gender internalization and resistance to gender norms in each smoking group. We expected that never smokers would have low internalization of norms and high resistance, two factors that may help to protect against smoking initiation in women. Current smokers, who are still engaged in smoking behavior, were expected to have high internalization of norms and low resistance, two risk factors for smoking in women. We also expeced that ex-smokers, who at one time engaged in a risky behavior but were able to cease it, would share some features with current smokers (high internalization of norms, a risk factor) and some with never smokers (high resistance to norms, a protective factor). We focused on the latter group's changed behavior (from smoking to not smoking) over time; we believe that the group's past smoking behavior is consistent with a higher vulnerability to internalized normative pressure, whereas their currently high level of resistance to normative pressures permits them to achieve the relatively rare status of ex-smokers.

\section{Hypotheses}

1. Above and beyond demographic factors, internalization of and resistance to gendered social pressures were expected to play an important role in predicting smoking status. In particular, current smokers would be characterized as young, with low levels of education and income, high levels of gender norm internalization, and low levels of critical consciousness; ex-smokers would be characterized as older, having high levels of education and income, high levels of gender norm internalization, and high levels of critical consciousness; never smokers would be characterized as having high levels of education and income, low levels of gender norm internalization, and high levels of critical consciousness.

2. Among both current and ex-smokers, feminist consciousness was expected to correlate with endorsing "independence" and "liberation" as reasons for smoking initiation.

\section{METHOD}

\section{Participants and Procedure}

Participants were 945 women who took part in a national random digit dialing study focused primarily on attitudes and behaviors related to smoking and weight. Data were collected in the summer and fall of 1998 by trained interviewers at the University of Michigan Institute for Social Research, who used Computer Assisted Telephone Interview (CATI) software. Interviews consisted of approximately 180 questions (depending on smoking history and responses) and lasted approximately $30 \mathrm{~min}$ (see Pomerleau, Zucker, Brouwer, Pomerleau, \& Stewart, 2001; Pomerleau, Zucker, \& Stewart, 2001, 
for more details on the sample). Seventy-five percent of eligible women agreed to participate.

Potential participants were stratified on smoking status to produce the following groups: current smokers $(n=371)$, ex-smokers $(n=215)$, and neversmokers $(n=359)$. All participants were required to meet the following criteria: age 18-45 (to have a range of adult female smokers before the onset of menopause), not currently pregnant or having given birth within the past 6 weeks, and not currently using any nicotine replacement product. To be eligible to participate as a smoker, respondents were required to have smoked at least 4 days per week for at least 1 year, with cigarette smoking their primary form of tobacco use; because the survey was intended to focus on women who smoked enough that tobacco use could have an impact on their weight, women who were only "weekend" smokers were excluded. To be eligible to participate as an ex-smoker, respondents were required to have been abstinent from smoking for at least 6 months and to have met at one time the same criteria specified for smokers-that is, to have smoked at least 4 days per week for at least 1 year, with cigarette smoking their primary form of tobacco use. Never-smokers were required to have smoked fewer than 100 cigarettes in their lifetime and not to be currently using cigarettes or any other form of tobacco. These criteria are consistent with those used by the CDC in their study of US smoking prevalence (CDC, 2004c).

Participants were asked to indicate their identification with multiple racial/ethnic groups. Seventyfour percent of women identified as European American only. The other women identified as African American (12.4\%), Asian or Pacific Islander (4\%), Latina $(8.3 \%)$, Middle Eastern $(0.3 \%)$, and American or Alaskan Native $(8.7 \%$; percentages sum to more than 100 because categories were not mutually exclusive). Because the literature has suggested that Whiteness may be especially associated with vulnerability to thinness pressures (e.g., Fallon, 1990; Harris, 1994), and because no other racial/ethnic group was large enough for separate analyses, we assessed "ethnicity" in terms of being European American. That is, we compared women whose sole ethnic heritage was European American to all other groups combined.

\section{Measures}

Demographic information was collected from the participants. Some items were used to assess place in the social structure.
First, two indicators of social class were assessed: Education was measured as the highest level completed of nine categories, which ranged from "less than eighth grade" to "earned a postgraduate degree." Household income was assessed as the annual income for the household based on eight categories, which ranged from "under $\$ 5,000$ " to " $\$ 100,000$ or more."

Second, ethnicity was created as a dichotomous variable by collapsing participants' identities into "European American only" or "not European American only."

Third, age was calculated as a continuous variable; we used the difference between the participant's birth date and the date on which she was interviewed.

Finally, Body Mass Index (BMI) is a proportional measure of weight that accounts for height; it is determined by the formula BMI $=\mathrm{kg} / \mathrm{M}^{2}$. It was included as a "control" variable whenever weight concern was assessed in order to identify the role of weight concern, net of actual weight or body mass.

\section{Reasons for Smoking}

Participants were asked eight questions about why they first began to smoke (e.g., social reasons, the buzz, taste, coping with stress). Two items that could indicate feminism as a cause for smoking were smoking as a sign of independence and smoking as a sign of liberation. Both of these items were rated on a 4-point Likert scale, that ranged from 1 (not at all important) to 4 (very important); the correlation of these two items $(r=.05, n s)$ was the same for both current and ex-smokers.

There were two measures of internalization of gender pressures. First, embodied femininity (BayCheng et al., 2002) measured the degree to which participants had internalized feminine standards of body size, appearance, and beauty. The composite measure consisted of 12 items. Six of these items were drawn from the internalization subscale of the Sociocultural Attitudes Toward Appearance Questionnaire (SATAQ; for a more detailed review of the scale's reliability and validity, see Heinberg, Thompson, \& Stormer, 1995), which pertains to women's acceptance of mainstream criteria and pressures regarding embodied femininity and to women's use of media images of female models as a standard by which to measure their own femininity and attractiveness (e.g., "Women who appear in advertisements project the type of appearance that I see 
as my goal"). The remaining six items used to measure embodied femininity concern the degree of importance to participants of various feminine appearance goals (e.g., looking young, having flattering clothes, having a feminine voice; Pomerleau, Zucker, \& Stewart, 2001). The index as a whole encompasses both self-evaluations of appearance and level of investment in different aspects of appearance. All 12 items were measured on a 4-point Likert scale that ranged from 1 (not at all) to 4 (very important); $\alpha=$ .76 .

Second, weight concern (Bay-Cheng et al., 2002) was assessed with nine items that measure level of concern and preoccupation with one's weight. One cluster of five items asked participants to anticipate how they might react to a weight gain of 10 pounds. One item asked respondents to rate their level of agreement with the statement "I am willing to take a risk with my health in order to be slim," such that 1 indicated strong disagreement and 4 indicated strong agreement. The final three items on this scale assessed respondents' dieting habits and fear of weight gain. These were rated on a 5-point scale where 1 indicated little or no anxiety about weight gain and 5 indicated extreme or omnipresent weight concern. The index consisted of the mean of the nine standardized variables; $\alpha=.73$.

Finally, there were two measures of critical consciousness. The first was advertising skepticism. This measure consisted, in part, of the five item News Media Bias Scale (Price, Huang, \& Tewksbury, 1997), which was slightly modified by changing the word "media" to the word "advertisements" in all items (e.g., "Much of what appears in advertisements is untrustworthy," "It's smart to be skeptical of advertisements"). We developed two additional items, "Advertisements often encourage people to take risks with their health" and "Advertisements often promote sexist values," which were more directly related to the topic of this research. All seven items were rated on a 4-point scale $(1=$ strongly disagree, $4=$ strongly agree), and were combined into a scale based on the mean ratings of the items; $\alpha=.62$.

The second measure of critical consciousness, feminist consciousness, was based on Gurin and her colleagues' methods for assessing women's group consciousness (Gurin et al., 1980; Gurin \& Townsend, 1986). Participants were presented with two items to assess group identification and cognitive centrality, "How much do you feel you have in common with most women?" and "How often in your everyday life do you think about being a woman and what you have in common with other women?", which were rated on a 4-point scale $(1=$ nothing, $4=$ a lot ; and $1=$ never, $4=$ often, respectively). In addition, evaluative stance toward the social group was measured with a feeling thermometer. Participants were asked to rate their feelings toward a number of groups, including "women," the group of interest here, on a feeling thermometer that ranged from 0 (cool/unfavorable) through 50 (neutral) through 100 (warm/favorable). Each of the preceding three items was standardized individually with a mean of zero and a standard deviation of one, and then combined into a scale; $\alpha=.55$. Although the alpha is low, this seems reasonable given that there are only three items in the scale, and we decided to use it based on theoretical grounds. Furthermore, if any of the three items were dropped, the alpha value dropped further.

\section{RESULTS}

The correlations of key variables are presented in Table I. All demographic variables were correlated with each other in the expected ways, as were the body image variables. The two critical consciousness variables were moderately positively correlated.

Hypothesis 1, which predicted smoking status, was tested with discriminant function analysis (Klecka, 1980; Silva \& Stam, 1995). This test is appropriate when the dependent variable is categorical with three or more groups and the researcher is interested in using a set of independent variables ("discriminating variables") to predict membership in the distinct groups of the dependent variable (Klecka, 1980).

The first step for discriminant analysis requires the determination of group differences on the independent variables (Silva \& Stam, 1995), which are presented in Table II. Ex-smokers were significantly older and more weight concerned than current-and never-smokers. Current smokers had significantly less education and lower income than both the ex- and never-smokers; they also had significantly lower scores than ex-smokers on embodied femininity and advertising skepticism. There were no group differences on BMI, ethnicity, and feminist consciousness.

Next, all independent variables (embodied femininity, weight concern, feminist consciousness, and advertising skepticism, with age, education, household income, BMI, and European American) were entered as predictors of smoking status in the 
Table I. Intercorrelations of All Variables

\begin{tabular}{|c|c|c|c|c|c|c|c|c|}
\hline & 1 & 2 & 3 & 4 & 5 & 6 & 7 & 8 \\
\hline \multicolumn{9}{|l|}{ 1. Age } \\
\hline 2. Education & $.13^{* * *}$ & & & & & & & \\
\hline 3. Household income & $.22^{* * *}$ & $.32^{* * *}$ & & & & & & \\
\hline 4. BMI & $.09^{* *}$ & $-.12^{* * *}$ & $-.17^{* * *}$ & & & & & \\
\hline 5. European American & $.08^{*}$ & $.08^{*}$ & $.19^{* * *}$ & $-.13^{* * *}$ & & & & \\
\hline 6. Embodied femininity & $-.09^{* *}$ & -.00 & $.10^{* *}$ & -.04 & $.09^{* *}$ & & & \\
\hline 7. Weight concern & -.02 & .05 & .05 & $.21^{* * *}$ & $-.11^{* *}$ & $.51^{* * *}$ & & \\
\hline 8. Advertising skepticism & .03 & $.21^{* * * *}$ & $.12^{* * *}$ & -.04 & .12 & -.04 & .04 & \\
\hline 9. Feminist consciousness & $.09^{* *}$ & $.20^{* * *}$ & $.16^{* * *}$ & $-.08^{*}$ & $.12^{* * *}$ & $.15^{* * *}$ & $.10^{* *}$ & $.11^{* *}$ \\
\hline
\end{tabular}

${ }^{*} p<.05 ;{ }^{* *} p<.01 ;{ }^{* * *} p<.001$.

discriminant analysis. A total of 87 women had missing values for one or more of these variables; the majority were missing on household income $(n=$ $63)$ and/or BMI $(n=28)$. We imputed the mean for participants' missing data on household income and BMI (Bernaards \& Sijtsma, 2000), which reduced the number of missing cases to three (the basic results of the analysis did not differ when the analyses were rerun with nonimputed variables).

Discriminant analysis will produce a number of unique functions that is equal to the number of groups of the categorical variable minus one or to the number of discriminating variables (whichever is fewer; Klecka, 1980). These functions are combinations of the discriminating independent variables; the combinations are produced in such a way that the member of the groups that comprise the dependent variable are maximally different in their mean levels of the combined independent variables (Klecka, 1980). In our case, two functions were produced based on the 942 participants with valid data, and the overall analysis correctly classified $49 \%$ of the cases $(51 \%$ of current smokers, $45 \%$ of ex-smokers, and $50 \%$ of never smokers). These numbers were better than would have been expected by chance (33.3\% in each group). Both functions were significant, Wilks's $\lambda$ for function $1=.84, \chi^{2}=163.36$, $p<.001$; Wilks's $\lambda$ for function $2=.94, \chi^{2}=55.81$, $p<.001$.

Table III shows that education, feminist consciousness, and BMI correlated most strongly with Function 1 and that age, weight concern, household income, embodied femininity, advertising skepticism, and European American correlated most strongly with Function 2. Figure 1 plots the group centroids; it shows that never smokers are high on Function 1 (they are more educated, have higher levels of feminist consciousness, and have higher BMIs), whereas current smokers are low on Function 1 (they are less educated, have lower levels of feminist consciousness, and have lower BMIs). Exsmokers are high on Function 2 (they are older, have higher household incomes, are more weight concerned, score higher on embodied femininity, are

Table II. ANOVAs on All Variables by Smoking Status

\begin{tabular}{|c|c|c|c|c|}
\hline \multirow[b]{2}{*}{ Variable (range) } & \multicolumn{3}{|c|}{$M(S D)$} & \multirow[b]{2}{*}{ Significance } \\
\hline & Current smokers & Ex-smokers & Never smokers & \\
\hline Age (18-45) & $34.18^{a}(7.66)$ & $37.08^{b}(6.66)$ & $33.50^{a}(8.00)$ & $F(2,929)=15.62^{* * *}$ \\
\hline Education $^{c}(1-9)$ & $5.01^{a}(1.39)$ & $5.82^{b}(1.83)$ & $6.10^{b}(1.57)$ & $F(2,942)=46.27^{* * *}$ \\
\hline Household Income $^{d}(1-8)$ & $4.80^{a}(1.61)$ & $5.46^{b}(1.57)$ & $5.21^{b}(1.66)$ & $F(2,942)=12.41^{* * *}$ \\
\hline BMI (15.35-58.36) & $24.78^{a}(5.67)$ & $25.30^{a}(5.13)$ & $25.20^{a}(5.44)$ & $F(2,942)=.82, n s$ \\
\hline European American (\% yes) & $73.3 \%$ & $79.0 \%$ & $72.0 \%$ & $\chi^{2}(2,942)=3.60, n s$ \\
\hline Embodied femininity (1-4) & $2.73^{a}(.55)$ & $2.87^{b}(.47)$ & $2.79^{a b}(.44)$ & $F(2,942)=5.40^{* *}$ \\
\hline Weight concern $(-1.64-1.63)$ & $-.04^{a}(.70)$ & $.12^{b}(.57)$ & $-.03^{a}(.55)$ & $F(2,942)=5.68^{* *}$ \\
\hline Advertising skepticism (1-4) & $3.18^{a}(.45)$ & $3.29^{b}(.48)$ & $3.20^{a b}(.44)$ & $F(2,942)=3.81^{*}$ \\
\hline Feminist consciousness $(-2.77-1.20)$ & $-.07^{a}(.74)$ & $.03^{a}(.72)$ & $.05^{a}(.71)$ & $F(2,942)=3.21^{*}$ \\
\hline
\end{tabular}

${ }^{a b}$ Means in the same row that do not share superscripts differ at $p<.05$ by the Scheffé test.

${ }^{c}$ For education, $5=$ graduated from technical or trade school, $6=$ some college.

${ }^{d}$ For income, $4=\$ 25,000-34,999,5=\$ 35,000-49,999$.

${ }^{*} p<.05 ;{ }^{* *} p<.01 ;{ }^{* * *} p<.001$. 
Table III. Correlations Between Discriminating Variables and Discriminant Functions (Function Structure Matrix)

\begin{tabular}{lcc}
\hline \multicolumn{1}{c}{ Variable } & Function 1 & Function 2 \\
\hline Education & $.90^{a}$ & .10 \\
Feminist Consciousness & $.23^{a}$ & .07 \\
BMI & $.10^{a}$ & .08 \\
Age & -.05 & $.76^{a}$ \\
Weight concern & -.06 & $.42^{a}$ \\
Household income & .36 & $.41^{a}$ \\
Embodied femininity & .18 & $.35^{a}$ \\
Advertising skepticism & .09 & $.33^{a}$ \\
European American & -.01 & $.25^{a}$ \\
\hline
\end{tabular}

${ }^{a}$ Variable is most highly correlated with this function.

more skeptical of advertising, and are more likely to be European American).

Contrary to Hypothesis 2, current smokers' feminist consciousness was unrelated both to reports of having started to smoke as a sign of independence, $r=.03, n s$, and reports of having started to smoke as a sign of liberation, $r=.05, n s$. Similarly, ex-smokers' feminist consciousness was unrelated both to reports of having started to smoke as a sign of independence, $r=.11, n s$, and reports of having started to smoke as a sign of liberation, $r=.05, n s$.

\section{DISCUSSION}

As expected, the three groups differed on certain social structural factors. Most notably, the cur- rent smokers had significantly lower levels of education and annual household income than either the ex- or the never smokers at the bivariate level. At the multivariate level, education most strongly correlated with Function 1 (on which current smokers scored low and never smokers scored high) and income most strongly correlated with Function 2 (on which ex-smokers scored high). This finding is consistent with many studies that have demonstrated a steep SES gradient in smoking behavior (e.g, Smith \& Fiore, 1999). It is interesting that these two SES variables correlated with different functions. This is consistent with other research (see, e.g., Winkleby, Jatulis, Frank, \& Fortmann, 1992) that showed separate effects of education and income on healthrelated risk factors, and it suggests that future researchers should continue to deconstruct SES in this way. Although the current data are correlational and cannot address causality, they suggest that some types of information attained from education may help people to avoid smoking initiation, whereas other material resources or conditions may be helpful in promoting smoking cessation.

In addition, as expected, ex-smokers were significantly older than current and never smokers; older women have had a longer time in which to initiate and then quit smoking. Regardless of why they began to smoke, they soon became physically addicted, and may have had a hard time quitting. In addition, as women age a variety of life stage-related motives (e.g., pregnancy—see Britton, 1998; Condit,

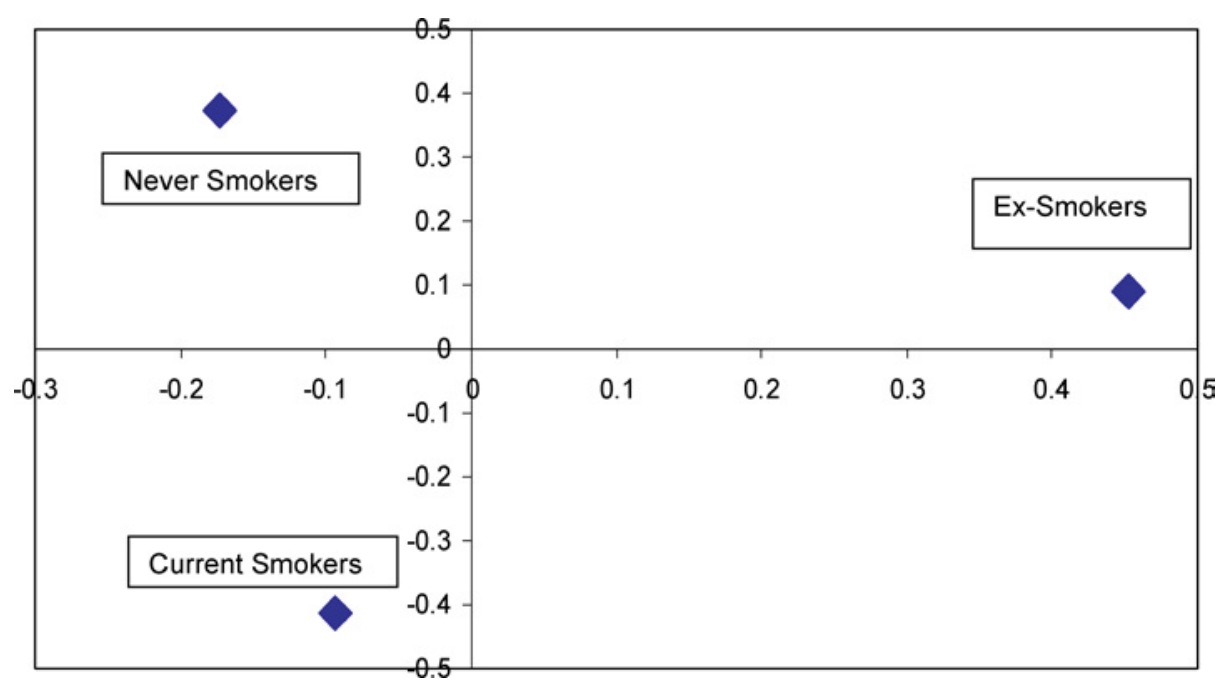

Fig. 1. Group centroids plot from discriminant function analysis $(Y$-axis $=$ Function 1 : Education, Feminist Consciousness and BMI; $X$-axis $=$ Function 2: Age, Weight Concern, Income, Embodied Femininity, Advertising Skepticism, European American). 
1996) and generally increasing concerns about health may increase women's desire to quit and not restart. Women who were European American were equally likely to be current, ex-, and never smokers. In the discriminant analysis, however, being European American correlated most strongly with Function 2 (ex-smokers). This variable clustered not only with higher income, but also with embodied femininity and weight concern in the discriminant analysis, which supports other findings that European American women are equally or more weight concerned than various groups of Women of Color (e.g., BayCheng et al., 2002; Harris, 1994).

There were bivariate differences by smoking status on the internalization of gendered social norms. Ex-smokers were significantly higher than both current and never smokers on both embodied femininity and weight concern. Similarly, in the discriminant analysis, embodied femininity and weight concern were both positively correlated with Function 2 (on which ex-smokers scored high). It is interesting that current smokers and never smokers did not differ on this dimension, which perhaps indicates that some level of preoccupation with appearance is normative for women in this age range. At the same time, ex-smokers showed very high levels of internalization of thinness pressures and weight concern. It is possible that the very act of quitting smoking, with the attendant weight gain, actually increased women's preoccupation with gendered appearance pressures. Without longitudinal data we cannot know what the ex-smokers valued before or during their quitting process. This finding, however, may help to explain high levels of recidivism among other women who are trying to quit smoking. It may be that advertising skepticism is necessary to counter the effects of gendered social norms and remain abstinent.

In terms of resistance to gendered social norms, advertising skepticism emerged as an important variable that differentiates smoking status. At the bivariate level, current smokers scored significantly lower than ex-smokers (but not differently than never smokers) on this construct. At the multivariate level, advertising skepticism was most strongly related to Function 2, and it discriminated the ex-smokers (i.e., those who have quit) from the two other groups. Women are exposed to many cigarette advertisements, particularly in print media, that convey strong prescriptive messages about women's lives, including their roles in the workplace and relationships (e.g., Boyd, 1996-1997; Boyd et al., 1999-2000; Boyd et al., 2003; Condit, 1996; Cortese, 1999; Kellner, 1988).
The data from this study suggest that being skeptical of advertisements may assist women to resist the prescriptions enough to help them stop smoking. Although our data were correlational, the results of this study suggest that skepticism may serve to help smokers quit. Of course we cannot tell from our results whether the ex-smokers acquired advertising skepticism after initiation to cigarettes and it assisted them in their quit efforts, whether something about the process of quitting heightened their critical reading of advertisements, or whether the relation is spurious. In the second case, this heightened critical perspective might help them to remain abstinent. Results of studies that are longitudinal and/or experimental in design would help to clarify these issues.

Two sets of results address the competing claims that feminism might either promote or inhibit smoking behavior (Jacobson, 1982; Rausch et al., 1987; Zucker et al., 2001). Present levels of feminist consciousness, for both current and ex-smokers, were unrelated to identification of either "independence" or "liberation" as reasons for starting to smoke. In addition, feminist consciousness discriminated between current smokers (low) and never smokers (high) in the multivariate analysis. These data suggest that the women in our study did not start smoking for feminist reasons or as a result of changes wrought by the women's movement. Furthermore, the data suggest that feminist consciousness may serve as a protective factor against smoking. The association of feminist consciousness with never smoker status suggests that there may be something about this form of critical consciousness that is useful in resisting initiation, though this must be confirmed in longitudinal or experimental studies. A number of components of feminist consciousness, such as high self-esteem, the belief that women's worth is not completely determined by body size, and anger at the tobacco industry's objectification of women, may contribute to this relation. In a qualitative study, Pohl and Caplan (1998) found that feminist empowerment skills were related to quitting. Based on our findings, future research on prevention strategies that includes inculcation of these skills or development of prevention campaigns aimed at young people that emphasize features of critical consciousness is also warranted.

It is interesting, and contrary to the hypothesis, that scores on our assessments of critical consciousness (or resistance to gendered social norms) were associated with different functions. This suggests that 
psychological variables that are helpful for quitting smoking and for preventing initiation may be different. Pohl and Caplan's (1998) study of smokers combined feminist analysis with advertising skepticism; the resulting skills were related to quitting. It appears, however, that it may be useful to design studies to differentiate the impact of critical consciousness directed at the media or at women's status on both initiation and cessation of smoking.

The biggest limitation of this study is its crosssectional nature, which does not allow us to examine causal relations. In addition, some of the scales had relatively low levels of internal consistency. Although the sample was quite large and representative of U.S. women aged 18-45, there were not enough Women of Color in each ethnic group to perform separate analyses-an important limitation because there is considerable cultural variation in the value placed on thinness in women. If these methodological limitations are addressed in future studies, broader generalizability would be possible.

This study is important in that it demonstrates that resistance to and internalization of gendered social pressures, particularly those concerning women's appearance, weight, and self-worth, are related to the health risk behavior of smoking in women. Future researchers should examine how these pressures may differentially affect groups not considered in this study. Our findings may be helpful in designing prevention programs, and it will be important to extend this research to young and adolescent girls because the majority of smoking is initiated before age 18 (CDC, 2004b). In addition, we limited the ages of women in the study to 18-45 years so that the findings would not be complicated by physical changes associated with menopause that may affect both smoking behavior and body weight. In future studies, it will be important to include older women because issues related to their bodies may have complex effects. For instance, many women gain weight as they age and may experience ageist discrimination after they complete their reproductive years; on the other hand, some women feel an increasing sense of confidence and power as they age and may not feel as pressured to conform to men's and society's views of them (e.g., Zucker, Ostrove, \& Stewart, 2002). Furthermore, the women in this study may be too young to have been affected by the Virginia Slims liberation messages about smoking. Perhaps the message about liberation was more persuasive in making smoking attractive to earlier generations of women.
The role of gendered social norms with regard to smoking in men also warrants further study. Although the issues are different, there is as strong a construction of the masculine smoker as there is of the feminine smoker (e.g., Kellner, 1988). Men who are susceptible to pressures to demonstrate their strength, virility, and authenticity as "real men" may be particularly vulnerable to cigarette advertisements. Furthermore, if the pressure on men to have lean, fit bodies continues to increase, more men may be hesitant to face the likely weight gain upon smoking cessation. In this era of media saturation, it has become ever more important to identify effective ways of supporting both women's and men's mental and physical health in the face of advertising pressures that undermine it.

\section{ACKNOWLEDGMENTS}

This project was supported, in part, by Grant 031672 from the Robert Wood Johnson Foundation. The authors thank Laura Klem from the University of Michigan Center for Statistical Consultation and Research for advice on the statistical analysis and Joan M. Ostrove and Ami M. Lynch for editorial assistance on earlier drafts of the manuscript.

\section{REFERENCES}

Bancroft, A., Wiltshire, S., Parry, O., \& Amos, A. (2003). "It's like an addiction first thing. . .afterwards it's like a habit:" Daily smoking behaviour among people living in areas of deprivation. Social Science and Medicine, 56, 1261-1267.

Bay-Cheng, L. Y., Zucker, A. N., Stewart, A. J., \& Pomerleau, C. S. (2002). Linking femininity, weight concern, and mental health among Latina, Black, and White women. Psychology of Women Quarterly, 26, 36-45.

Bernaards, C. A., \& Sijtsma, K. (2000). Influence of imputation and EM methods on factor analysis when item nonresponse in questionnaire data is non-ignorable. Multivariate Behavioral Research, 35, 321-364.

Britton, G. A. (1998). A review of women and tobacco: Have we come such a long way? Journal of Obstetric, Gynecologic, and Neonatal Nursing, 27, 241-249.

Bordo, S. (1993). Unbearable weight: Feminism, Western culture, and the body. Berkeley, CA: University of California Press.

Boyd, C. J. (1996-1997). Smoke and the 'F' word: Women and health. Michigan Feminist Studies, 11, 25-37.

Boyd, C. J., Boyd, T. C., \& Cash, J. L. (1999-2000). Why is Virginia slim? Women and cigarette advertising. International Quarterly of Community Health Education, 19, 19-31.

Boyd, T. C., Boyd, C. J. \& Greelee, T. B. (2003). A means to an end: Slim hopes and cigarette advertising. Health Promotion Practice, 4, 266-277.

Cash, T. F. \& Henry, P. E. (1995). Women's body images: Tthe results of a national survey in the U.S.A. Sex Roles, 33, 19-28. 
Centers for Disease Control and Prevention. (2004a). History of the 1964 Surgeon General's Report on smoking and health. Retrieved August 23, 2004, from http://www.cdc.gov/tob acco/30yrsgen.htm

Centers for Disease Control and Prevention. (2004b). Tobacco information and prevention source: Overview. Retrieved August 23, 2004, from http://www.cdc.gov/tobacco/issue.htm

Centers for Disease Control and Prevention. (2004c). Cigarette smoking among adults-United States, 2002. Morbidity and Mortality Weekly Report, 53, 427-431.

Centers for Disease Control and Prevention. (2004d). MediaSharp: Analyzing tobacco and alcohol messages. Retrieved August 23, 2004 from http://www.cdc.gov/ tobacco/educational_materials/mdiashrp.pdf

Chamberlain, K., \& O’Neill, D. (1998). Understanding social class differences in health: A qualitative analysis of smokers' health behaviors. Psychology and Health, 13, 1105-1119.

Chernin, K. (1981). The obsession: Reflections on the tyranny of slenderness. New York: Harper.

Condit, D. M. (1996). Tugging at pregnant consumers: Competing "Smoke!" "Don't Smoke!" media messages and their messengers. In R. L. Parrott \& C. M. Condit (Eds.), Evaluating women's health messages: A resource book (pp. 139-153). Thousand Oaks, CA: Sage.

Cortese, A. J. (1999). Provocateur: Images of women and minorities in advertising. Lanham, MD: Rowman \& Littlefield.

Crawford, M., \& Unger, R. (2004). Women and gender: A feminist psychology (4th ed.). Boston: McGraw-Hill.

Dedobbeleer, N., Beland, F., Contandriopoulos, A., \& Adrian, M. (2004). Gender and the social context of smoking behaviour. Social Science and Medicine, 58, 1-12.

Elkind, A. K. (1985). The social definition of women's smoking behaviour. Social Science and Medicine, 20, 1269-1278.

Ernster, V. L. (1985). Mixed messages for women: A social history of cigarette smoking and advertising. New York State Journal of Medicine, 85, 335-341.

Fallon, A. (1990). Culture in the mirror: Sociocultural determinants of body image. In T. F. Cash \& T. Pruzinsky (Eds.), Body images: Development, deviance, and change (pp. 80109). New York: Guilford.

Field, A. E., Cheung, L., Wolf, A. M., Herzog, D. B., Gortmaker, S. L., \& Colditz, G. A. (1999). Exposure to the mass media and weight concerns among girls. Pediatrics, 103, E361-E365.

Gerend, M. A., Boyle, R. G., Peterson, C. B., \& Hatsukami, D. K. (1998). Eating behavior and weight control among women using smokeless tobacco, cigarettes, and normal controls. $A d$ dictive Behaviors, 23, 171-178.

Gilman, S. E., Abrams, D. B., \& Buka, S. L. (2003). Socioeconomic status over the life course and stages of cigarette use: Initiation, regular use, and cessation. Journal of Epidemiological and Community Health, 57, 802-808.

Graham, H. (1992). Surviving by smoking. In S. Wilkinson \& C. Kitzinger (Eds.), Women and health: Feminist perspectives (pp. 102-123). London: Taylor and Francis.

Graham, H., \& Der, G. (1999). Patterns and predictors of smoking cessation among British women. Health Promotion International, 14, 231-239.

Gurin, P., Miller, A., \& Gurin, G. (1980). Stratum identification and consciousness. Social Psychology Quarterly, 43, 30-47.

Gurin, P., \& Townsend, A. (1986). Properties of gender identity and their implications for gender consciousness. British Journal of Social Psychology, 25, 139-148.

Harrell, J. S., Bangdiwala, S. I., Deng, S., Webb, J. P., \& Bradley, C. (1998). Smoking initiation in youth: The roles of gender, race, socioeconomics, and developmental status. Journal of Adolescent Health, 23, 271-279.

Harris, S. M. (1994). Racial differences in predictors of college women's body image attitudes. Women and Health, 21, 89104.
Heinberg, L. J., \& Thompson, J. K. (1995). Body image and televised images of thinness and attractiveness: A controlled laboratory investigation. Journal of Social and Clinical Psychology, 14, 325-338.

Heinberg, L. J., Thompson, J. K. \& Stormer, S. (1995). Development and validation of the Sociocultural Attitudes Towards Appearance Questionnaire. International Journal of Eating Disorders, 17, 81-89.

Jacobson, B. (1982). The ladykillers: Why smoking is a feminist issue. New York: Continuum.

Jarvis, M. J. (1997). Patterns and predictors of smoking cessation in the general population. In C. T. Bolliger \& K. O. Fagerstrom (Eds.), The tobacco epidemic (pp. 151-164). Basel: Karger.

Kellner, D. (1988). Reading images critically: Toward a postmodern pedagogy. Journal of Education, 10, 31-52.

Kilbourne, J. (1994). Still killing us softly: Advertising and the obsession with thinness. In P. Fallon, M. A. Katzman, \& S. C. Wooley (Eds.), Feminist perspectives on eating disorders (pp. 395-418). New York: Guilford.

Klecka, W. R. (1980). Discriminant analysis. Newbury Park, CA: Sage.

Klesges, R. C., \& Klesges, L. M. (1988). Cigarette smoking as a dieting strategy in a university population. International Journal of Eating Disorders, 7, 413-419.

MacDonald, M., \& Wright, N. E. (2002). Cigarette smoking and the disenfranchisement of adolescent girls: A discourse of resistance? Health Care for Women International, 23, 281-305.

Manfredi, C., Lacey, L. P., Warnecke, R., \& Petraitis, J. (1998). Sociopsychological correlates of motivation to quit smoking among low-SES African American women. Health Education and Behavior, 25, 304-318.

Morrow, M., Ngoc, D. H., Hoang, T. T., \& Trinh, T. H. (2002). Smoking and young women in Vietnam: The influence of normative gender roles. Social Science and Medicine, 55, 681-690.

Pampel, F. C. (2003). Age and education patterns of smoking among women in high-income nations. Social Science \& Medicine, 57, 1505-1514.

Peet, M., \& Reed, B. G. (1999). Activism in an introductory women's studies course: Connected learning through the implementation of praxis. Women's Studies Quarterly, 27, 21-35.

Pfau, M., Nelson, M. L., \& Moster, M. (1996). Women and smoking: Consequences and solutions. In R. L. Parrott \& C. M. Condit (Eds.), Evaluating women's health messages: A resource book (pp. 139-153). Thousand Oaks, CA: Sage.

Pohl, J. M., \& Caplan, D. (1998). Smoking cessation: Using group intervention methods to treat low-income women. Nurse Practitioner, 23, 13-39.

Pomerleau, C. S., Berman, B. A., Gritz, E. R., Marks, J. L. \& Goeters, S. (1994). Why women smoke. In R. R. Watson (Ed.), Drug and alcohol abuse reviews. Vol. 5: Addictive behaviors in women (pp. 39-70). Totowa, NJ: Humana Press.

Pomerleau, C. S., Zucker, A. N., Brouwer, R. J. N., Pomerleau, O. F., \& Stewart, A. J. (2001). Race differences in weight concerns among women smokers: Results from two independent samples. Addictive Behaviors, 26, 651-663.

Pomerleau, C. S., Zucker, A. N., \& Stewart, A. J. (2001). Characterizing concerns about post-cessation weight gain: Results from a national survey of women smokers. Nicotine and Tobacco Research, 3, 51-60.

Price, V., Huang, L., \& Tewksbury, D. (1997). Third-person effects of news coverage: Orientations toward media. Journalism and Mass Communication Quarterly, 74, 525-540.

Rausch, J. C., Hopp, J., \& White, R. (1987). Determinants of smoking behavior among nurses. Journal of Drug Education, 17, 365-377.

Rodin, J., Silberstein, L., \& Striegel-Moore, R. (1984). Women and weight: A normative discontent. Nebraska Symposium on Motivation, 32, 267-307. 
Silva, A. P. D., \& Stam, A. (1995). Discriminant analysis. In L. G. Grimm \& P. R. Yarnold (Eds.), Reading and understanding multivariate statistics (p. 277-318). Washington, DC: American Psychological Association.

Smith, S. S., \& Fiore, M. C. (1999). The epidemiology of tobacco use, dependence, and cessation in the United States. Primary Care, 26, 433-461.

Stronks, K., van de Mheen, H. D., Looman, C. W. N., \& Mackenbach, J. P. (1997). Cultural, material, and psychosocial correlates of the socioeconomic gradient in smoking behavior among adults. Preventive Medicine, 26, 754-766.

Waldron, I. (1991). Patterns and causes of gender differences in smoking. Social Science \& Medicine, 32, 9891005.
Winkleby, M. A., Jatulis, D. E., Frank, E., \& Fortmann, S. P. (1992). Socioeconomic status and health: How education, income, and occupation contribute to risk factors for cardiovascular disease. American Journal of Public Health, 82, 816-820.

Wolf, N. (1991). The beauty myth. London: Chatto \& Windus.

Zucker, A. N., Harrell, Z. A., Miner-Rubino, K., Stewart, A. J., Pomerleau, C. S., \& Boyd, C. J. (2001). Smoking in college women: The role of thinness pressures, media exposure, and critical consciousness. Psychology of Women Quarterly, 25, 233-241.

Zucker, A. N., Ostrove, J. M., \& Stewart, A. J. (2002). Collegeeducated women's personality development in adulthood: Perceptions and age differences. Psychology and Aging, 17, 236-244. 